Research Article

\title{
Mechanical and Rheological Properties of 3D Printable Cement Composites
}

Maathar Al Qasimi, Dhafer Mana Al Zulayq, Mostafa Seifan *

School of Engineering, Faculty of Science and Engineering, The University of Waikato, Hamilton, New

Zealand; E-Mails: $\quad$ maather.alqasmi@hotmail.com; zaf-121@outlook.sa;

mostafa.seifan@waikato.ac.nz

* Correspondence: Mostafa Seifan; E-Mail: mostafa.seifan@waikato.ac.nz

Academic Editor: Luciano Ombres

Special Issue: Fiber Composite Materials and Civil Engineering Applications

Recent Progress in Materials

2020, volume 2 , issue 4

doi:10.21926/rpm.2004022
Received: July 29, 2020

Accepted: October 20, 2020

Published: October 23, 2020

\begin{abstract}
Additive manufacturing is a recent revolution in the construction field since cementitious materials became printable. This extrusion technique has enabled the construction of very complex geometry with a reduction in costs, time and labour interventions. This study aims to evaluate the possibility of reinforcing 3D printable cementitious composites with the use of nano and micro materials, particularly nano silica, micro silica and microfibrillated cellulose (MFC) which are known for their ability to enhance the fresh and hardened properties of cement-based composites. Rheology property test, flowability and mechanical properties are the types of tests performed to evaluate the fresh and hardened properties of mortar modified with the rested additives. The results show the addition of MFC of $0.4 \%$ (of total solid matter) can significantly enhance the mechanical property. In addition, the presence of MFC (at $0.4 \%$ of total solid matter) can reduce the pressure required to extrude the mortar, enabling a steady state extrusion. It was also found that $1 \%$ nano silica addition significantly improves the mechanical properties and minimizes segregation in the failure surface.
\end{abstract}

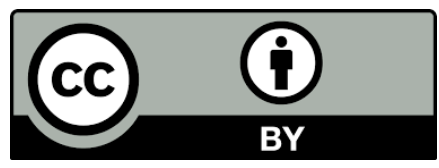

(C) 2020 by the author. This is an open access article distributed under the conditions of the Creative Commons by Attribution License, which permits unrestricted use, distribution, and reproduction in any medium or format, provided the original work is correctly cited. 


\section{Keywords}

Microfibrillated cellulose; 3D printing; cement; mortar; rheology; mechanical properties; flowability

\section{Introduction}

3D printing is an automation technique that recently aims to solve many problems associated with the construction industry. The first attempts in using cement-based materials for additive manufacturing were made by Pegna in 1997 [1]. Additive manufacturing with cement-based materials is a new technology that facilitates the construction process and adds many advantages to the construction field such as eliminating the construction cost by reducing the time-consuming processes from using the conventional method [2], enhancing the design flexibility of building shapes and their structural elements, and improving the environmental and safety aspects of the structures. The possibility of reducing the number of formworks in the construction offers a major advantage in the concrete structure since the formwork represents around $35 \%$ of the total construction cost $[3,4]$. In addition, the process of formwork assembly is labour intensive. The technology of 3D printing has the potential to overcome these challenges besides reducing material wastages and the amount of labour needed to accomplish a project [5-7]. The shift toward additive manufacturing is necessary since it has superior advantages over conventional construction techniques as well as improving design and architectural freedom by designing flexible shapes of structural components and reducing labour intervention in the construction process which can significantly reduce the workplace accidents.

Although there are different factors that affect the properties and printability of the concrete mixtures, the mixture composition has a great influence on the final properties of 3D printed concrete. For instance, the size of aggregates is an influential factor in the final strength of printed concrete but there are considerations to use up to a specific size allowing the printing process. Mostly fine particles are used for many different mixes of concrete when 3D printed. This limitation is associated with the size of the nozzle and the capability of the machine to continuously extrude. The maximum size of sand particles that have been used in the majority of studies is not more than $2 \mathrm{~mm}[3,8]$ but in some cases, aggregates up to the size of $10 \mathrm{~mm}$ are used [9].

The presence of additives which can provide additional features to the mixes is crucial. Additives are added to the mortar in a low dosage, but they provide numerous positive benefits for the resulting fresh and hardened concrete. In this context, the availability of additives plays an important role in 3D printing of concrete. In research performed by Le et al. [10,11], the effect of different additives such as fly ash, fibre and silica fume on the mechanical properties of concrete was investigated. Generally, open time and setting can be controlled using superplasticizer, retarder or additives [12]. In order to improve the workability of concrete for example, the potential chemical admixture option is water-reducing agents known as plasticizers or for a quick set which is needed in 3D printing, the mixture should contain accelerator agents.

Modifying cement composite with nanoparticles and microparticles is widely used in practical applications. Using nano silica as an additive in concrete attracts many researchers' attention due to the similarities in chemical compositions between nano silica and concrete and its ability to 
enhance the properties of cement composites. Likewise, micro fibre materials can be added to enhance the extrudability behavior and improve flowability. In addition, additives are often used to reduce the environmental impact of concrete. In terms of reducing carbon dioxide footprint, microfibrillated cellulose (MFC) is sustainable and environmentally friendly as well as helping to improve the mixture by decreasing bleeding and segregation. Cao et al [13] found the presence of cellulose nanocrystals in cement composite can increase the flexural strength of paste and this feature can minimize the formation of cracks induced with the matrix or between the printed layers. Additionally, it has been reported that cellulose materials can affect the hydration process [14]. The study performed by Fu et al. [15] showed cellulose nanocrystals increase the cement hydration from $5-20 \%$ depending on the types of cement. In another investigation, an experiment was performed to improve the fracture characteristics of concrete; initial results illustrated that the increase of micro-and nanofibers in combination to $3 \%$ increased the fracture energy by more than $50 \%$ [16].

Microfibrillated cellulose is found to be one of the best materials for preventing crack growth which is one of the major issues in 3D printing of concrete however the mechanical properties of such mixtures need to be investigated. Therefore, the initial purpose of the study was to determine the optimum $\mathrm{w} / \mathrm{c}$ ratio that is suitable for $3 \mathrm{D}$ printing and the ultimate aims were to investigate the effects of nano and micro additives on the printability and mechanical properties of the cementitious composite.

\section{Materials and Methods}

\subsection{Design Mix and Proportions}

Mortar mix consists of cement, sand and water. Three types of additives were chosen to be tested: Nano silica (N.S.), Micro silica (M.S.) and microfibrillated cellulose (MFC). Microfibrillated cellulose (Exilva P 01-L) was provided by Borregaard at $2 \mathrm{wt} \%$ solid content. Initially, the influence of superplasticizer was investigated with different water to cement ratios. Superplasticizer was used in all mixes since it improves the flowability behavior. Cemix, a commercially available plasticizer was purchased from a domestic supplier and used in this study. The initial investigation was to study the manual extrudability of the pastes through a syringe nozzle of $5.5 \mathrm{~mm}$ diameter. This method helped determine the optimum water to cement $(\mathrm{w} / \mathrm{c})$ ratio to be considered to proceed with the remaining experiments. The ratio of $\mathrm{w} / \mathrm{c}$, cement to sand and superplasticizer amount was kept constant for all samples. Water to cement ratio was 0.39 and the cement to sand ratio was selected with 3 as a base mix and then different concentrations of additives were added to produce different mixes. Prior to the experiment, the sand used in the study was sieved through a $0.5 \mathrm{~mm}$ sieve to avoid clogging in the nozzle.

Table 1 shows the mixes and their proportions. All dry materials were mixed with mixer for 30 seconds, while water was mixed with superplasticizer then two-thirds of the liquid content was added to the dry matter and mixed for approximately three minutes. After that, the remaining liquid was added and mixed for two minutes. Sample 1 had no additive added and, was used as a reference sample. For samples 2 and 3, N.S. was added to $1 \%$ and 3\% of cement mass. Micro silica was added in sample 3 of $1 \%$ of cement mass. For mix 5 and mix 6 MFC was added at $0.4 \%$ and $0.73 \%$ of the total solid matter was added respectively. All mixes used in the experiments are summarized in Table 1. 
Table 1 Mixes and their proportions.

\begin{tabular}{llllll}
\hline Samples & $\begin{array}{l}\text { Cement-to- } \\
\text { sand ratio }\end{array}$ & $\begin{array}{l}\text { Water-to- } \\
\text { binder ratio }\end{array}$ & $\begin{array}{l}\text { Superplasticizer } \\
(\mathbf{m l})\end{array}$ & Additive & $\begin{array}{l}\text { Amount of additive } \\
\text { (\%) }\end{array}$ \\
\hline Control & 3 & 0.39 & 2 & 0 & 0 \\
$1 \%$ N.S. & 3 & 0.39 & 2 & N.S. & 1 \\
$3 \%$ N.S. & 3 & 0.39 & 2 & N.S. & 3 \\
$1 \%$ M.S. & 3 & 0.39 & 2 & M.S. & 1 \\
$0.4 \%$ MFC & 3 & 0.39 & 2 & MFC & 0.4 (solid matter) \\
$0.73 \%$ MFC & 3 & 0.39 & 2 & MFC & 0.73 (solid matter) \\
\hline
\end{tabular}

\subsection{Characterization of Particles}

The morphology of additives along with cement and sand was determined using scanning electron microscopy (SEM; Hitachi S-4700). Briefly, the dried particles were placed on sticky carbon tape and attached to the aluminium stub then the samples were platinum coated using a sputter coater (Hitachi E1030) to minimize the image disturbances. Finally, the samples were inserted into a high vacuum chamber and imaging was performed at $15 \mathrm{kV}$.

\subsection{Fresh State Properties Tests}

After preparing the fresh mixes, the slump test and rheology tests were conducted. A flow table test was done based on ASTM 1437-16 [17], to study the workability and flowability behavior of the mortars. It was performed using a slump cone with a size of $100 \mathrm{~mm}$ bottom diameter and $70 \mathrm{~mm}$ top diameter that was placed on the flat plate as shown in Figure 1a. The mix was poured into the cone up to half the height and then compacted by tamping 20 times to ensure uniform filling of the mold. The second layer was added until the cone was filled, and tamping was applied as well. The cone then was lifted, the flat plate was dropped and then the spread diameter was measured from two directions as in Figure $1 \mathrm{~b}$.
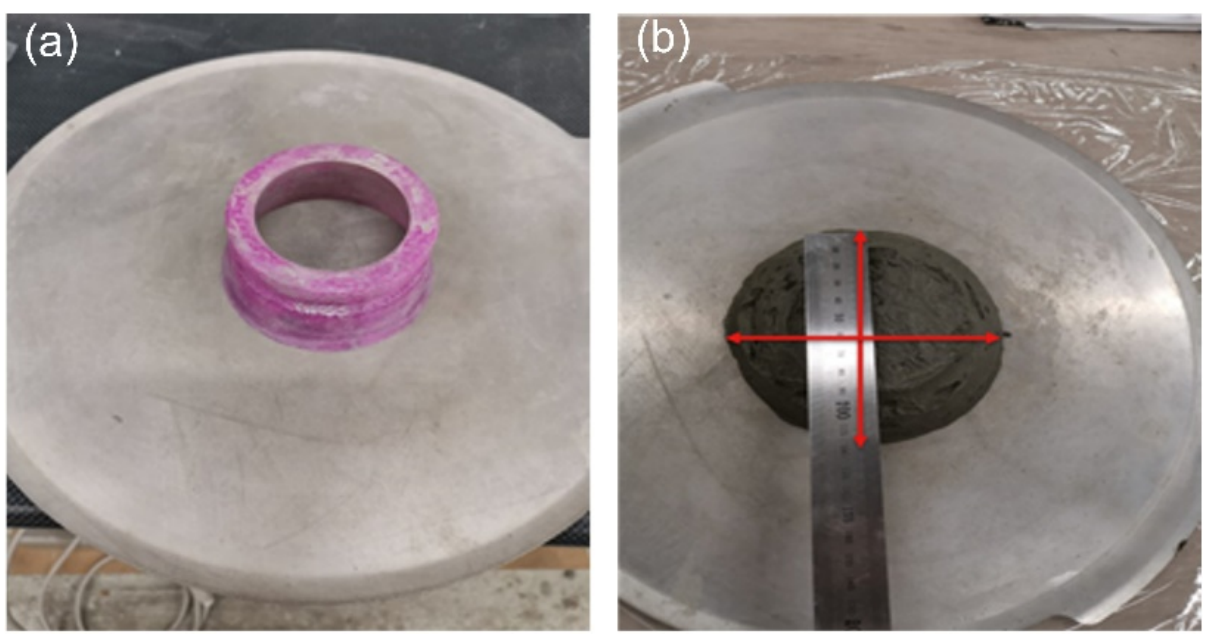

Figure 1 a) Slump test tools and b) spread diameter measurements. 


\subsection{Rheology}

Extrudability is known as the capacity of the mortar to be extruded and is assessed from syringe test data. To study the extrudability of the mixtures, a set up as shown in Figure 2 was used. The rheology test was performed using an Instron machine, the syringe was filled with the mix for up to $60 \mathrm{~mm}$ and compacted to avoid air which might affect the pressure readings during the extrusion. It was attached to the machine and two different speeds were tested. Figure 3 shows that the piston was set to move with a speed of $4 \mathrm{~mm} / \mathrm{s}$ from the displacement 0 to $15 \mathrm{~mm}$ and then with $2 \mathrm{~mm} / \mathrm{s}$ speed from displacement 15 to $30 \mathrm{~mm}$. The resulting load readings were then used to calculate the total pressure applied to the samples. The average pressure formula for a predefined moving velocity is given in equation 1 :

$$
P=\frac{4 F}{\pi D^{2}}
$$

where $\mathrm{F}$ is the average force at the performed speed with the pressure and $\mathrm{D}$ is the diameter of the syringe.
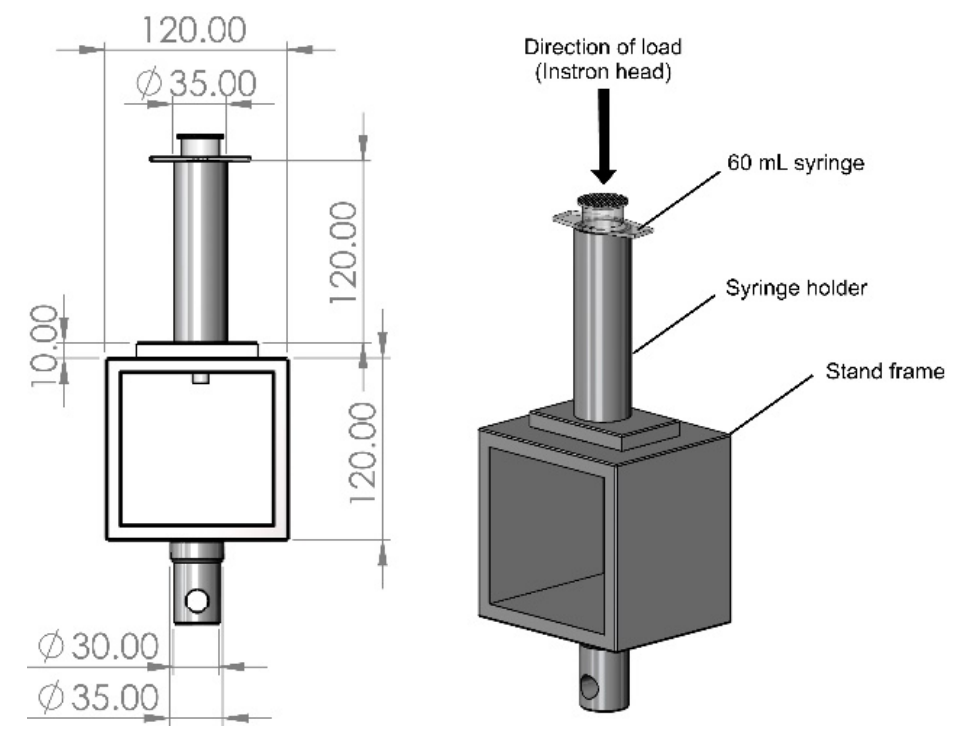

Figure 2 Set up used for extrudability experiment.
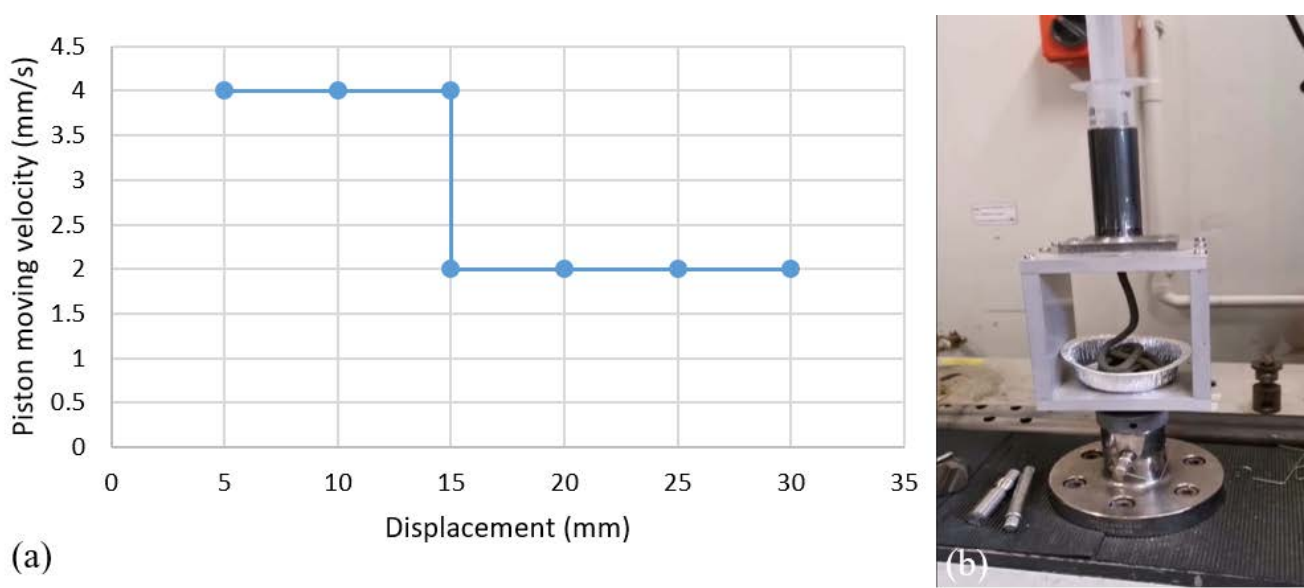

Figure 3 Piston moving velocity versus displacement. 


\subsection{Hardened State Properties Tests}

Samples were prepared for compressive and splitting strength tests which are the two main mechanical properties tests for cementitious materials. The tests were done by compacting the mortar inside molds of cylindrical shapes with a nominal diameter of $32 \mathrm{~mm}$ and $60 \mathrm{~mm}$ height. Three molds were prepared for compressive strength and the other three for the splitting test at 7 days and 28 days. The samples were left for 24 hours to dry before they were demolded then they were placed in a moist condition to be cured for 7 and 28 days to be tested accordingly. A compressive strength test was conducted based on ASTM C109-16 [18] while a splitting tensile strength test was done following ASTM C496-16 [19].

\section{Results and Discussion}

\subsection{Characterization}

To observe the morphology of particles, they were analyzed using SEM. Figure 4a shows the SEM micrograph of sand used in the mixes. Generally, the sands were irregular shapes and had a size of less than $50 \mu \mathrm{m}$. Figure $4 \mathrm{~b}$ represents the micrograph of cement particles which were significantly smaller than the sand particles. As shown in Figure 4c, N.S. particles were in a range size of 10-20 $\mathrm{nm}$. Figure $4 \mathrm{~d}$ shows the average particle size of M.S. from SEM which is about $10 \mu \mathrm{m}$.
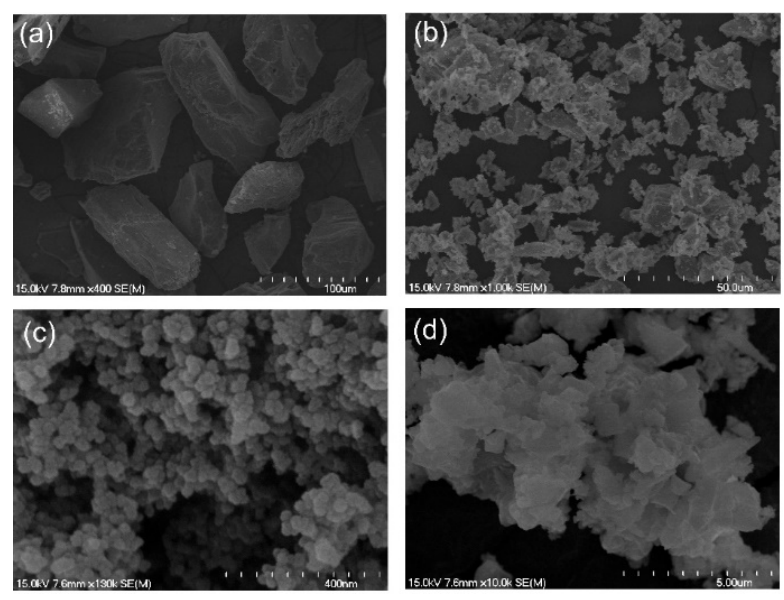

Figure 4 SEM micrograph of (a) sand (b) cement (c) N.S. and (d) M.S.

\subsection{Preliminary Study}

Six different $\mathrm{w} / \mathrm{c}$ ratio experiments were performed to determine the most feasible ratio suitable for printing purposes. Water to cement ratio was evaluated at different values $0.33,0.36,0.37,0.39$, 0.4 and 0.42 . The ratio of cement to sand and the amount of plasticizer were kept constant throughout these experiments. Figure 5 a shows the samples extruded from the syringe to test by hand how smoothly it flowed. Figure $5 b$ shows the samples after one day being left to dry and harden.

As expected, using higher water to cement ratio than 0.4 made the sample flow more easily and difficult to handle. Using 0.33 and 0.36 of $\mathrm{w} / \mathrm{c}$ ratio required more pressure applied to extrude the mortar out of the nozzle and was not smoothly extruded, therefore the water content was not 
sufficient to ease the flow of the mortar. The optimum $\mathrm{w} / \mathrm{c}$ ratio was noticed in $0.39 \mathrm{mix}$, the mortar was extruded continuously and with relatively moderate pressure applied to extrude the mortar. Therefore, this ratio was chosen to be constant and applied to all samples to achieve proper results regarding strength of the samples based on the additive added.
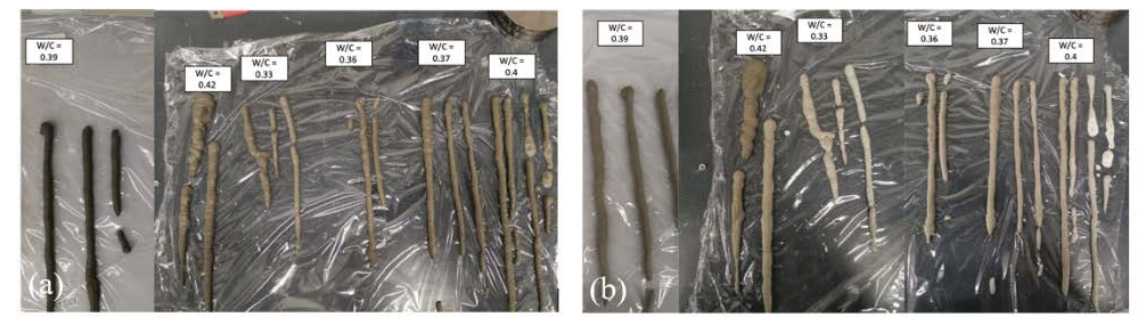

Figure 5 Visual inspection of extruded material for different w/c ratio at (a) first day and (b) second day.

\subsection{Workability Test}

The workability test is conducted to investigate the flowability behavior of the mixture. Typically, there are two types of geometrical measurements that can be taken as a result of the test: the difference between the initial and final height of the flow which is called the slump and the spread diameter which is known as slump flow. Figure 6 shows the values of the spread diameter for different mixes. It was noticed that adding the three types of additives overall decreased the flowability of the mortar compared to the control sample. As the N.S. content increased in the mixture, the workability decreased. A similar study was performed with a 0.4 water to binder ratio and a similar percentage of N.S. which resulted in a reduction in the workability of cement-based composite [20]. The slump flow of the control fresh sample was $205 \mathrm{~mm}$ which was significantly dropped by adding $1 \%$ and $3 \%$ of N.S. by $75 \mathrm{~mm}$ and $90 \mathrm{~mm}$ respectively. This decrease in slump flow when adding N.S. was explained by Yu at al. and the addition of N.S. will increase the sample's demand for water, thus the probability of lubrication of water with interparticle voids decreases which result in an increase of yield stress and plastic viscosity of cementitious composites [21]. In terms of MFC, the mixture with $0.4 \%$ resulted in a higher spread diameter as compared to the $0.73 \%$ mix. It was found that the increase of MFC caused a reduction in the workability of the mixture due to the lack of water in the mixture as cellulose fibres are classified as hydrophilic, and they tend to absorb water while mixing [22].

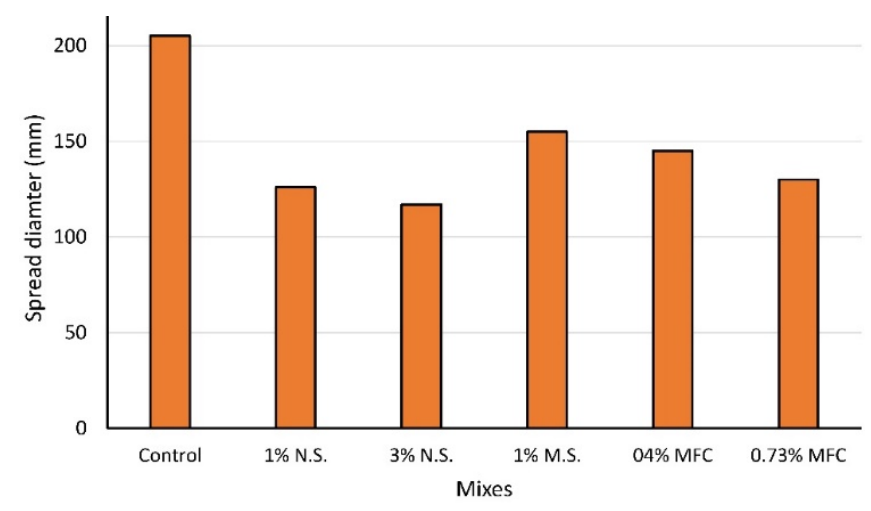

Figure 6 Results of spread diameter of all mixes. 


\subsection{Rheology Behavior}

Rheology behavior is strongly dependent on the extrudability of the mixes. The syringe test or rheology test is used to test the flow properties of the paste. This test is essential as many factors depend on it such as durability, strength and consolidation [23]. The mixes were filled inside the syringe for up to $60 \mathrm{~mm}$ and compacted with a steel rod. Two different speed setups $4 \mathrm{~mm} / \mathrm{s}$ for 0 to 15 compressive extension and $2 \mathrm{~mm} / \mathrm{s}$ for 15 to $30 \mathrm{~mm}$ were used. For most samples, the extrusion was performed four times. When the samples were ready, they were attached to the Instron machine to test their extrudability. Figures 7a-f show the output data from rheology experiments from Instron. The average pressure was calculated for each case for 0 to $15 \mathrm{~mm}$ extension which was under $4 \mathrm{~mm} / \mathrm{s}$ extrusion speed and 15 to $30 \mathrm{~mm}$ extension under $2 \mathrm{~mm} / \mathrm{s}$ and was compared.

The overall trend of the relationship between extrusion speed and total pressure was noticed from the graphs. When the speed was reduced from $4 \mathrm{~mm} / \mathrm{s}$ to $2 \mathrm{~mm} / \mathrm{s}$ the required average pressure decreased. For the control mix, the pressure required for the extrusion for up to $15 \mathrm{~mm}$ extension was calculated as $52.12 \mathrm{kPa}$ (Figure 7a) while the average pressure over $2 \mathrm{~mm} / \mathrm{s}$ speed was $49.9 \mathrm{kPa}$. The sample was extruded very smoothly; the extruded layers were relatively stable.

With $1 \%$ N.S. and 3\% N.S. in Figure 7b-c, the mixes experienced segregation and they were relatively dry compared to the control sample; however, the total pressure versus one compressive extension for $3 \%$ N.S. was off the trend and the extrusion was not very smooth. The average pressure under $4 \mathrm{~mm} / \mathrm{s}$ extrusion speed was $70.8 \mathrm{kPa}$ and $204.4 \mathrm{kPa}$ for $1 \%$ N.S. and 3\% N.S., respectively. The values were $67.65 \mathrm{kPa}$ for $1 \%$ N.S. and $335.2 \mathrm{kPa}$ for $3 \%$ N.S. under $2 \mathrm{~mm} / \mathrm{s}$ extrusion speed. Figure $7 d$ shows the results of adding $1 \%$ M.S. The mix was wet and not stable although the average pressure was $84.84 \mathrm{kPa}$ and $84.32 \mathrm{kPa}$ for $4 \mathrm{~mm} / \mathrm{s}$ and $2 \mathrm{~mm} / \mathrm{s}$, respectively, so it did not show much difference of average pressure between the two different speeds.

An experiment was performed using the aggregates (maximum size of $4 \mathrm{~mm}$ ), with two w/c ratios of 0.45 and 0.60 to evaluate the effect of MFC on concrete properties [24]. This study suggested that the addition of MFC influences the need of superplasticizer. The amount of superplasticizer used was restricted to be $2 \mathrm{ml}$ for all mixes however and this suggests the dose of SP to be $1 \%$ of the cement weight. The mentioned study stated that as MFC doses increase in the mixture, the plastic viscosity increases accordingly. The optimum extrusion was achieved when using $0.4 \% \mathrm{MFC}$. As it can be seen in Figure 7e, the mix was well extruded and buildable as the layers seemed to support themselves. The average pressure for $4 \mathrm{~mm} / \mathrm{s}$ and $2 \mathrm{~mm} / \mathrm{s}$ was $56.3 \mathrm{kPa}$ and $57.93 \mathrm{kPa}$, respectively. If the mixture does not have enough superplasticizer dosage, the mixture will tend to be stiff [24]. Therefore, among all the mixes, $0.4 \%$ MFC was the most suitable mix for the extrusion technique of a 3D printer as it had the smallest extrusion pressure at both rates; values close to the control sample extrusion pressure. Moreover, it exhibits the most stable shape, therefore that is a sign that adding MFC can improve the rheology behavior. 
Recent Progress in Materials 2020; 2(4), doi:10.21926/rpm.2004022
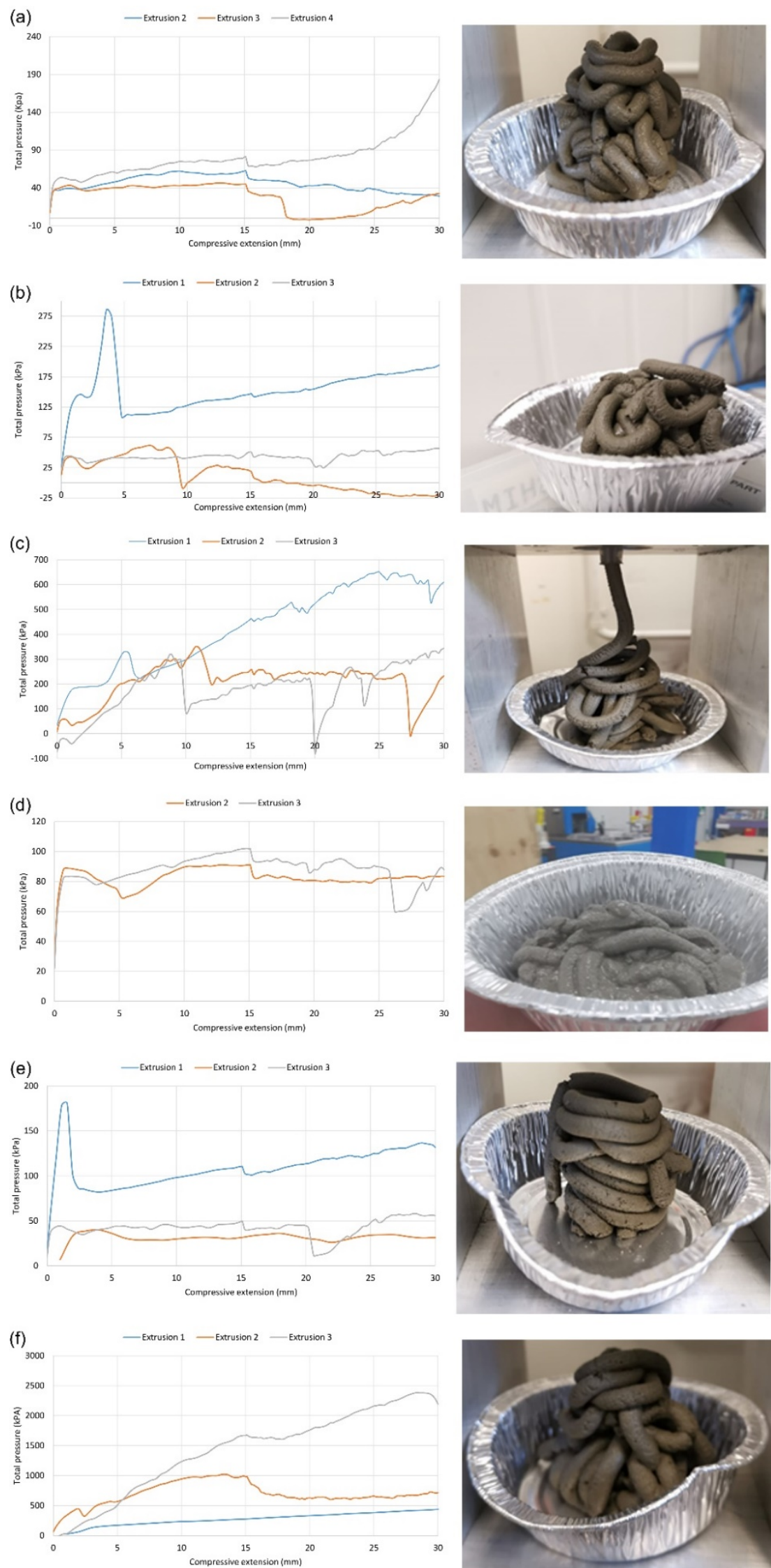

Figure 7 Output data from extruding a) control mix b) $1 \%$ N.S. c) $3 \%$ N.S. d) $1 \%$ M.S. e) $0.4 \%$ MFC and f) $0.73 \%$ MFC. 


\subsection{Mechanical Properties}

Concrete and mortar are usually strong in compression and weak in tensile therefore they are typically reinforced with steel to enhance their tensile strength. The compressive and splitting tensile strength tests were carried out at 7 days and 28 days. As was expected, the results of compressive strength and splitting strength showed an increase from 7 days to 28 days showing a reasonable strength development. Generally it is known that a lower w/c ratio would result in higher strength [24]. The results displayed in Figure 8 show the average compressive strength at 7 and 28 days. Theoretically, the compressive strength of concrete at seven days is two-thirds of the compressive strength at 28 days. Practically, it may increase more than $66 \%$ if an appropriate proportion of components and appropriate curing of the concrete were carried out. This rule was achieved with the addition of $1 \%$ of N.S., $0.73 \%$ and $0.4 \%$ of MFC to the mortar.

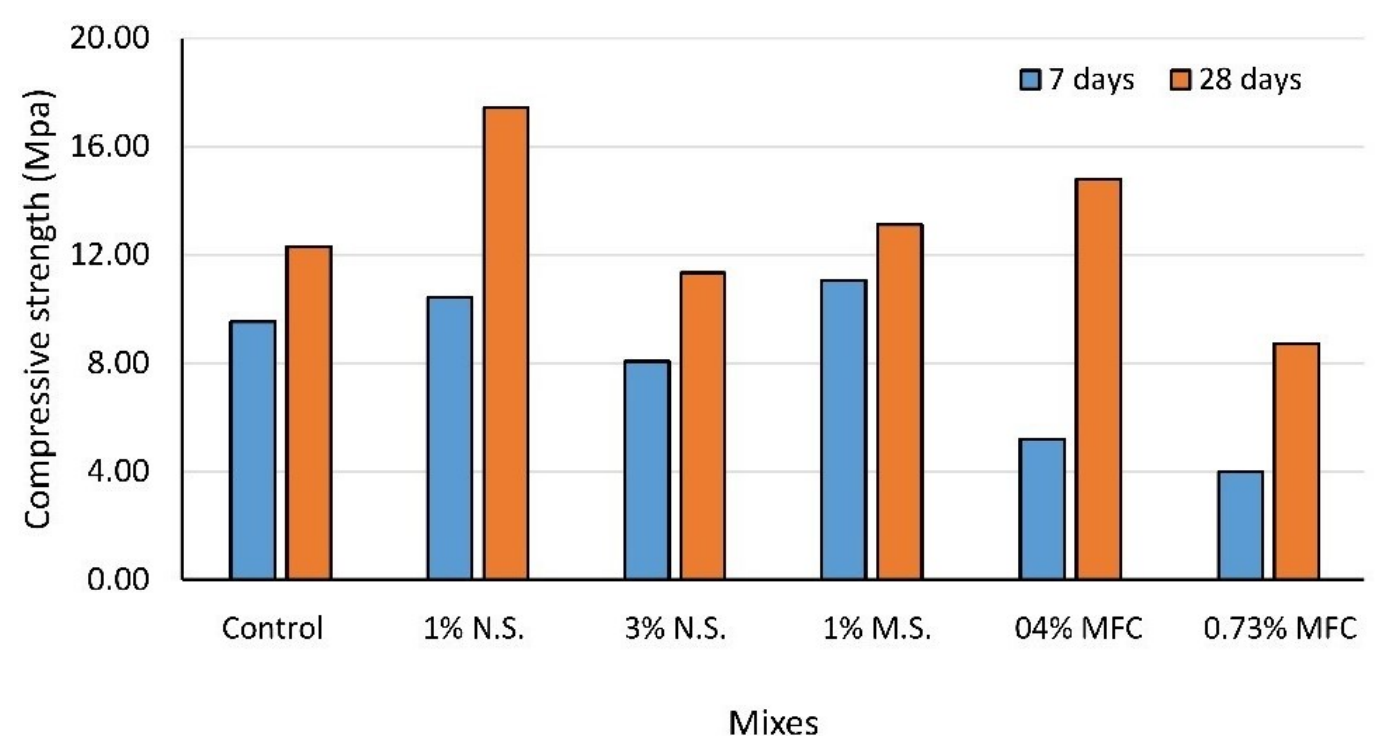

Figure 8 Average compressive strength values.

The optimum increase in compressive strength was achieved when using $0.4 \%$ of MFC and a significant increase of $185 \%$ of compressive strength at 28 days was observed in comparison with the 7 days strength. It can be noticed that the increase in the dose of MFC would result in a decrease in the compressive strength. It was studied that the type of fibril has a slight effect on mechanical properties. The fine fraction type resulted in a slight increase in contrast with the coarse type [24]. In another study, an investigation was performed using MFC with the cement to sand and w/c ratios of 0.41 and 0.53 respectively, and coarse aggregates size of $12.5 \mathrm{~mm}$. This study was undertaken to examine the effect of MFC percentage $(0.25 \%$ and $0.5 \%)$ on the concrete properties. It was noticed that the small percentage contributed to the most rise in peak load; this reduction in the load capacity with the MFC was reported to be caused by the poor dense structure resulting from the process of fibril mixing in the concrete [22].

However, $1 \%$ N.S. displayed the highest compressive strength after 28 days of curing and had an increase of $67.05 \%$ at 28 days compared to 7 days. Similarly, it was found the ultimate strength of concrete will be equivalent to the same percentage of N.S. used and other studies showed $1 \%$ of MFC results in higher strength than N.S. $[16,25]$. On the other hand, M.S. experienced only an 
increase of $18.5 \%$ of its compressive which is considered relatively low compared to the control mix which had a $29.07 \%$ increase.

Figure 9 shows the splitting tensile strength of all mixes. Splitting tensile strength is very weak in concrete, pastes and mortars due to their brittle nature. They develop cracks as soon as the tensile forces exceed their tensile strength. From visual inspection of the failure, surface of samples failed due to compression. As it can be seen from Figure 10, all of the specimens' surface failures are due to compression. In addition, it was noticed that microparticles such as M.S. and MFC can produce voids or segregation inside the failure surface which might indicate that those samples require more mixing to avoid air void.

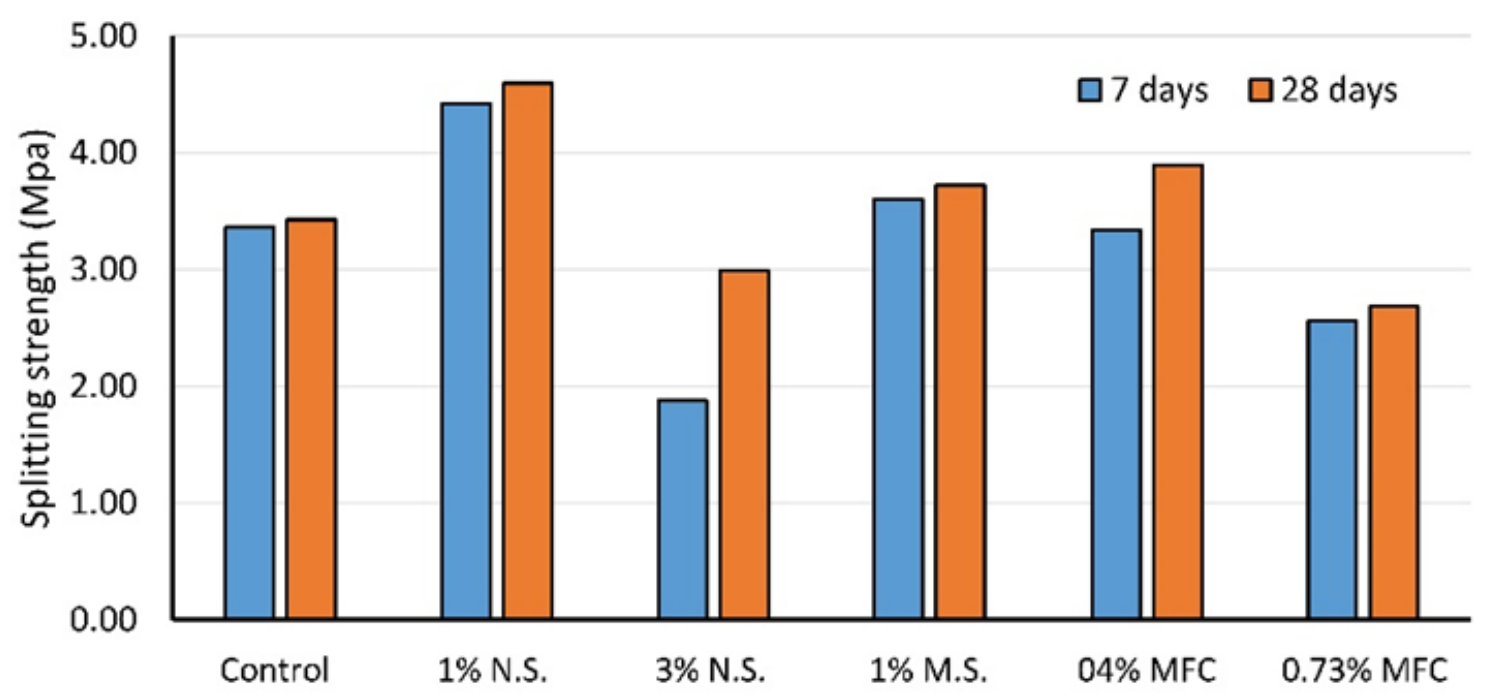

Mixes

Figure 9 Average splitting tensile strength values.
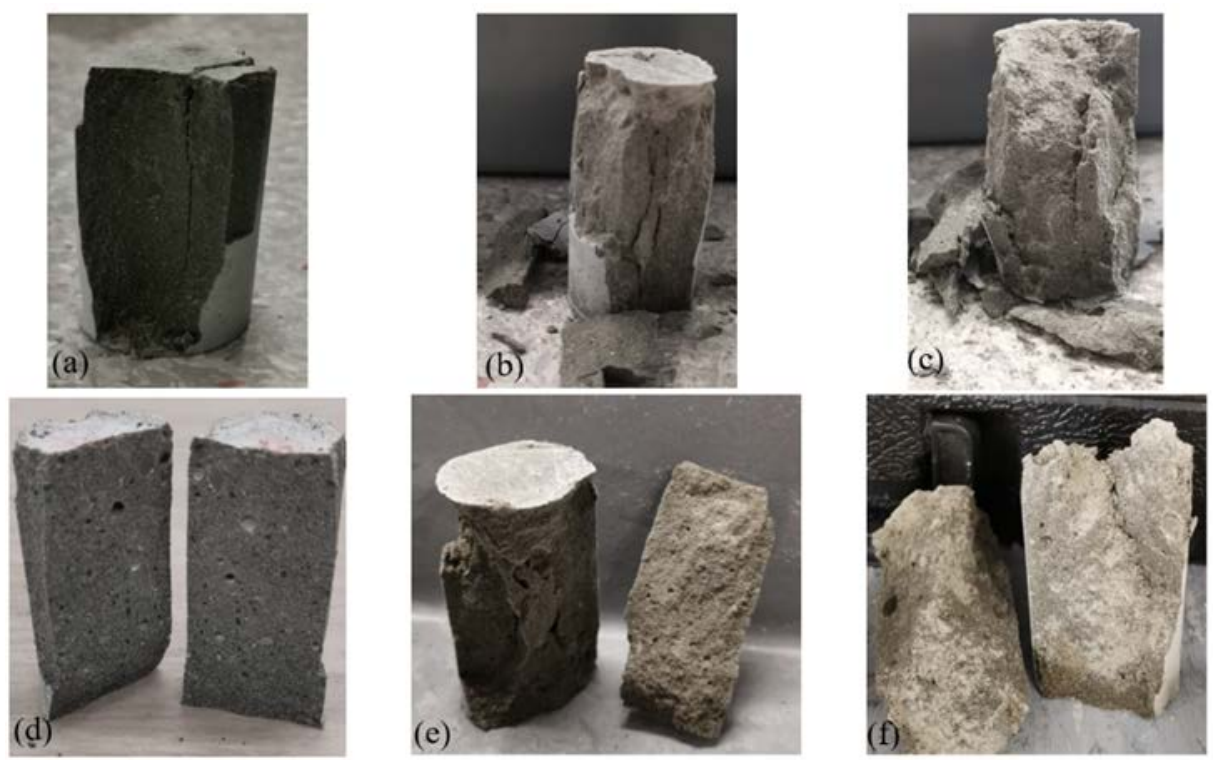

Figure 10 Surface failure due to compression a) control b) $1 \%$ N.S. c) $3 \%$ N.S. d) $1 \%$ M.S. e) $0.4 \%$ MFC and f) $0.73 \%$ MFC. 


\section{Conclusion}

The ideal mortar we aimed to achieve was the one which combines better flowability, extrudability and mechanical properties among the other mixes tested. Each of these tests was conducted and the results were evaluated for each mix and a comparison was established between them. Lower slump diameter was achieved with the addition of 3\% N.S. however the lower average pressure when extruding the mixes was obtained when adding $0.4 \%$ of MFC. Moreover, this exhibited the most stable layers. The largest increase in compressive strength was observed when adding $1 \%$ N.S., $0.73 \%$ MFC and $0.4 \%$ MFC. On the other hand, M.S. did not show noticeable improvements in mechanical properties. We can conclude that the optimum mix was achieved with 0.4 MFC; it proved that it enhances the flowability behaviors, extrudability as well as mechanical properties. In addition, it provides an opportunity to shift into a more sustainable option that can add value to the products.

\section{Author Contributions}

Maathar Al Qasimi: methodology, experimentation, formal analysis, visualization, writingoriginal draft preparation and contribution in the revision; Dhafer Mana Al Zulayq: analysis, visualization, validation and contribution in the revision; Mostafa Seifan: conceptualization, supervision, methodology, visualization, funding acquisition, manuscript preparation and revision.

\section{Competing Interests}

The authors have declared that no competing interests exist.

\section{References}

1. Pegna J. Exploratory investigation of solid freeform construction. Automat Constr. 1997; 5: 427437.

2. Rouhana C, Aoun M, Feak F, Jazzar ME. The reduction of construction duration by implementing contourontour crafting (3D printing). Proceedings of the 22nd Annual Conference of the International Group for Lean Construction; 2014 June 24; Oslo, Norway. Available From: https://www.researchgate.net/publication/265125098_The_Reduction_of_Construction_Dur ation_by_Implementing_Contour_Crafting_3D_Printing.

3. Perrot A, Rangeard D, Pierre A. Structural built-up of cement-based materials used for 3Dprinting extrusion techniques. Mater Struct. 2016; 49: 1213-1220.

4. Panda B, Tan MJ. Experimental study on mix proportion and fresh properties of fly ash based geopolymer for 3D concrete printing. Ceram Int. 2018; 44: 10258-10265.

5. Labonnote N, Rnnquist A, Manum B, Ruther P. Additive construction: State-of-the-art, challenges and opportunities. Automat Constr. 2016; 72: 347-366.

6. Gosselin C, Duballet R, Roux Ph, Gaudilliere N, Dirrenberger J, Morel Ph. Large-scale 3D printing of ultra-high performance concrete-a new processing route for architects and builders. Mater Design. 2016; 100: 102-109.

7. Wu P, Wang J, Wang X. A critical review of the use of 3D printing in the construction industry. Automat Constr. 2016; 68: 21-31. 
8. Pierre A, Lanos C, Estellé P. Extension of spread-slump formulae for yield stress evaluation. Appl Rheol. 2013; 23: 36-44.

9. Rushing TS, Stynoski PB, Barna LA, Al-Chaar GK, Burroughs JF, Shannon JD, et al. Investigation of concrete mixtures for additive construction. 3D Concrete Printing Technology. Melbourne: Elsevier Australia; 2019. p. 137-p. 160.

10. Le TT, Austin SA, Lim S, Buswell RA, Gibb AF, Thorpe T. Mix design and fresh properties for highperformance printing concrete. Mater Struct. 2012; 45: 1221-1232.

11. Le TT, Austin SA, Lim S, Buswell RA, Law R, Gibb AF, et al. Hardened properties of highperformance printing concrete. Cement Concrete Res. 2012; 42: 558-566.

12. Paul SC, Tay D, Panda B, Tan MJ. Fresh and hardened properties of 3D printable cementitious materials for building and construction. Arch Civ Mech Eng. 2018; 18: 311-319.

13. Cao Y, Weiss WJ, Youngblood J, Moon R, Zavattieri P. Performance-enhanced cementitious materials by cellulose nanocrystal additions. Production and Applications of Cellulose Nanomaterials. Peachtree Corners: Tappi Press; 2013. p. 135-p. 136.

14. Fu TF, Montes F, Suraneni P, Youngblood J. Cellulose nanomaterials as additives for cementitious materials. Cellulose-Reinforced Nanofibre Composites. Washington: U.S. Forest Service; 2017. p. 455-p. 482.

15. Fu TF, Montes F, Suraneni P, Youngblood J. The influence of cellulose nanocrystals on the hydration and flexural strength of Portland cement pastes. Polymers. 2017; 9: 424.

16. Peters SJ, Rushing TS, Lanids EN. Nanocellulose and microcellulose fibers for concrete. Transport Res Rec. 2010; 2142: 25-28.

17. Standard test method for flow of hydraulic cement mortar. West Conshohocken, PA: ASTM International; $2015 . \quad$ Available From: https://standards.globalspec.com/std/9981453/ASTM\%20C1437.

18. Standard test method for compressive strength of hydraulic cement mortars (using 2-in. or [50$\mathrm{mm}$ ] cube specimens). West Conshohocken, PA: ASTM International; 2011. Available From: https://standards.globalspec.com/std/1388771/astm-c109-c109m-s.

19. Standard test method for splitting tensile strength of cylindrical concrete specimens. West Conshohocken, PA: ASTM International; 1996. Available From: https://standards.globalspec.com/std/780808/astm-c496.

20. Rashad AM. A synopsis about the effect of nano- $\mathrm{Al}_{2} \mathrm{O}_{3}$, nano- $-\mathrm{Fe}_{2} \mathrm{O}_{3}$, nano- $-\mathrm{Fe}_{3} \mathrm{O}_{4}$ and nano-clay on some properties of cementitious materials-A short guide for civil engineer. Mater Design. 2013; 52: 143-157.

21. $\mathrm{Yu} R$, Spiesz $P$, Brouwers $H$. Effect of nano-silica on the hydration and microstructure development of Ultra-High Performance Concrete (UHPC) with a low binder amount. Constr Build Mater. 2014; 65: 140-150.

22. Zubair N. Effects of micro cellulose fibers addition on concrete mechanical properties underflexure and uniaxial tension. Victoria: University of Victoria; 2017.

23. Ferraris CF. Measurement of the rheological properties of high performance concrete: State of the art report. J Res Natl Inst Stan. 1999; 104: 461.

24. Nilsson J, Sargenius P. Effect of microfibrillar cellulose on concrete equivalent mortar fresh and hardened properties. Stockholm: The Royal Institute of Technology; 2011. 
25. Lavergne F, BelhadiJ R, Carriat A, Ben F. Effect of nano-silica particles on the hydration, the rheology and the strength development of a blended cement paste. Cement Concrete Comp. 2019; 95: 42-55.

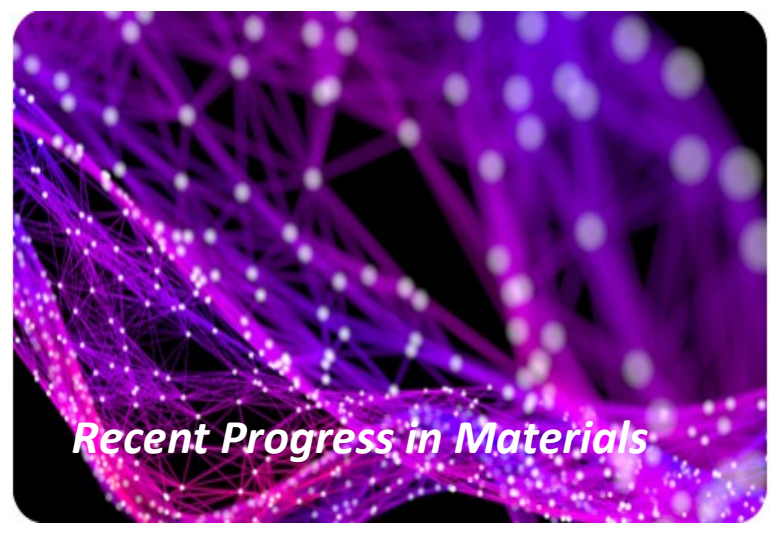

Enjoy Recent Progress in Materials by:

1. Submitting a manuscript

2. Joining in volunteer reviewer bank

3. Joining Editorial Board

4. Guest editing a special issue

For more details, please visit:

http://www.lidsen.com/journals/rpm 